DOI: 10.26730/1999-4125-2021-3-58-73

УДК (66.092.094.25.097+66.061):552.57
КАТАЛИТИЧЕСКОЕ ОЖИЖЕНИЕ УГЛЕЙ - ПЕРСПЕКТИВНЫЙ СПОСОБ ПРОИЗВОДСТВА МОТОРНЫХ ТОПЛИВ И ЦЕННЫХ ХИМИЧЕСКИХ СОЕДИНЕНИЙ

ЧАСТЬ 3. ФАКТОРЫ, ВЛИЯЮЩИЕ НА ПРОЦЕССЫ ОЖИЖЕНИЯ УГЛЕЙ: СТЕПЕНЬ УГЛЕФИКАЦИИ И СОСТАВ УГЛЯ

\title{
CATALYTIC LIQUEFACTION OF COALS - A PROMISING WAY TO PRODUCE MOTOR FUELS AND VALUABLE CHEMICAL COMPOUNDS \\ PART 3. FACTORS INFLUENCING THE PROCESSES OF COAL LIQUEFACTION: COAL RANK AND COAL COMPOSITION
}

\author{
Петров Иван Яковлевич ${ }^{1}$, \\ кандидат хим. наук, научный сотрудник, e-mail: ipetrov@kemcity.ru \\ Ivan Y. Petrov ${ }^{1}$, C. Sc. in Chemistry, Research Scientist \\ Осипов Алексей Васильевич ${ }^{2}$, \\ студент IV курса гр. ТЭб-172, e-mail: osipov.alexei1999@ gmail.com \\ Alexei V. Osipov ${ }^{2}$, student of the IV course, gr. TEb-172 \\ Ушаков Константин Юрьевич ${ }^{2}$, \\ ст. преподаватель, e-mail: as1sa2@mail.ru \\ Konstantin Y. Ushakov ${ }^{2}$, Senior Lecturer \\ Богомолов Александр Романович ${ }^{2,3}$,
} доктор техн. наук, профессор, заведующий кафедрой, e-mail: barom@ kuzstu.ru Alexander R. Bogomolov ${ }^{2,3}$, Dr. Sc. in Engineering, Professor, Head of the Department

Трясунов Борис Григорьевич ${ }^{1,2}$, доктор хим. наук, профессор, ведущий научный сотрудник, e-mail: btryasunov @ mail.ru

Boris G. Tryasunov ${ }^{1,2}$, Dr. Sc. in Chemistry, Professor, Leading Research Scientist

${ }^{1}$ Институт углехимии и химического материаловедения Федерального исследовательского центра угля и углехимии СО РАН, 650000, Россия, г. Кемерово, Советский проспект, 18 ${ }^{1}$ Institute of Coal Chemistry \& Chemical Materials Science, Federal Research Center of Coal \& Coal Chemistry, SB RAS, 18 Sovietsky Ave., Kemerovo 650000, Russian Federation

${ }^{2}$ Кузбасский государственный технический университет имени Т.Ф. Горбачева, 650000 , Россия, г. Кемерово, ул. Весенняя, 28

${ }^{2}$ T.F. Gorbachev Kuzbass State Technical University, 28 Vesennyaya Street, Kemerovo, 650000,

Russian Federation

${ }^{3}$ Институт теплофизики им. С.С. Кутателадзе СО РАН, 630090, Россия, г. Новосибирск, пр. Академика Лаврентьева, 1

${ }^{3}$ Kutateladze Institute of Thermophysics, SB RAS, 1 Lavrentiev Ave., Novosibirsk, 630090, Russian Federation

\footnotetext{
Аннотация:

Характеристики исходного угольного сырья, такие как ранг угля (степень углефикации), петрографический состав и минеральные компоненты, оказывают огромное влияние на выход и свойства продуктов, образующихся при ожижении твердых топлив. Выход жидких продуктов зависит от класса используемого угля и содержания в нем углерода. Максимальный выход дистиллируемых жидкостей наблюдается при содержании углерода 80-85\%, что соответствует битуминозньлм (каменным) углям. В случае низкосортных углей (лигнитов, сапропелитов, горючих сланцев и других твердых топлив) наблюдается достаточно высокая степень конверсии вследствие повышенного содержания кислорода ( 15-30\%), но при этом количество дистиллируемьх жидких продуктов
} 
снижается, а таких продуктов, как $\mathrm{CO}, \mathrm{CO}_{2}$ и $\mathrm{H}_{2} \mathrm{O}$, наоборот, возрастает. Среди петрографических компонентов углей наиболее реакционноспособными материалами, подвергающимися быстрым реакциям фрагментации, являются витринит и экзинит (липтинит). Мацераль типа инертинита, характеризующиеся более низкими значениями атомных отношений H/C, за некоторыми исключениями гораздо менее реакционноспособны. Минеральные вещества (силикаты, глины, пирит, карбонаты и др.), содержащиеся в углях, могут действовать и как катализаторы, и как ингибиторы процессов ожижения. Железосодержащче минералы способствуют реакциия гидрирования и крекинга угольного вещества, а также продуктов его превращтений. Присутствие в составе угля глинистых материалов (например, каолина) приводит к увеличению степени его превращения, но при этом также ускоряются реакции ароматизации, конденсации и коксообразования продуктов ожижения. B низкозольных углях с повышением содержания золь (т. е. с увеличением количества минеральных компонентов), как правило, возрастают как общая степень конверсии угля, так и выход жидких продуктов, но в высокозольных углях изменение содержания золь, по-видимому, не влияет на общую степень конверсии угля и выходы «угольных жидкостей».

Ключевые слова: ожижение углей, степень углефикации, атомное отношение Н/С, мацераль, минеральные компоненты угля, степень превращения угля

Информация о статье: поступило в редакцию 27.05.2021

\section{Abstract:}

Characteristics of initial coal raw materials, such as coal rank (degree of coalification), petrographic composition and mineral components, have a huge impact on the yield and properties of the products formed during the liquefaction of solid fuels. The yield of liquid products depends on the type of coal used and its carbon content. The maximum yield of distilled liquids is observed at a carbon content of $\sim 80-85 \%$, which corresponds to bituminous coals. In case of low-grade coals (lignites, sapropelites, oil shale and other solid fuels), a fairly high degree of conversion is observed due to the increased oxygen content ( 15-30\%), but the amount of distilled liquid products decreases, and that of such products as $\mathrm{CO}, \mathrm{CO}_{2}$ and $\mathrm{H}_{2} \mathrm{O}$, on the contrary, increases. Among the petrographic components of coals, vitrinite and exinite (liptinite) are the most reactive materials that undergo rapid fragmentation reactions. Macerals of the inertinite type, characterized by lower H/C atomic ratios, with some exceptions, are much less reactive. Mineral substances (silicates, clays, pyrite, carbonates, etc.) contained in coals can act both as catalysts and inhibitors of liquefaction processes. Ironcontaining minerals contribute to the hydrogenation and cracking reactions of coal matter, as well as to the products of its transformations. The presence of clay materials (for example, kaolin) in the composition of coal leads to an increase in the degree of its conversion, but at the same time, the reactions of aromatization, condensation and coke formation of liquefaction products are also accelerated. In low-ash coals, with an increase in the ash content (i.e., with a rise in the amount of mineral components), as a rule, both the total degree of coal conversion and the yield of liquid products increase, but in high-ash coals, changes in the ash contents do not seem to affect the total degree of coal conversion and yields of "coal liquids".

Keywords: coal liquefaction, degree of coalification, $\mathrm{H} / \mathrm{C}$ atomic ratio, macerals, mineral components of coal, coal conversion

Article info: received May 27, 2021

Во всех технологиях прямого ожижения угля (DCL) важную роль играют характеристики ожижаемого угольного сырья, в частности ранг угля (степень углефикации), его петрографический состав и содержащиеся в нем неорганические компоненты [1]. Данная обзорная статья посвящена рассмотрению роли каждого из этих факторов, а также их влиянию на степень превращения угля и выходы продуктов ожижения.

\section{Влияние степени углефикацчии (ранга) угля и химического состава его органической части}

Любой высокомолекулярный материал на углеродной основе со связями С-X или поперечными связями при термообработке может быть расщеплен на жидкие и/или газообразные продукты с меньшей молекулярной массой. Однако то, насколько хорошо твердое вещество будет подвергаться термораспаду, зависит как от природы и количества внутри- и межмолекулярных связей, так и от особенностей термического процесса, используемого для разрушения структуры высокомолекулярного материала (в частности, от возможности рекомбинации образующихся более мелких реакционноспособных фрагментов и протекания ретроградных реакций формирования вторичных высокомолекулярных продуктов) [2]. 


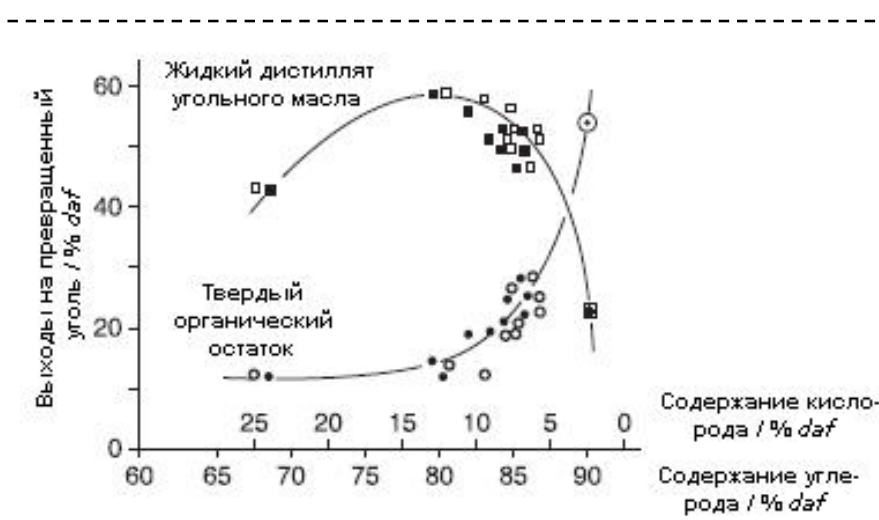

Рис. 1. Влияние класса угля (содержания углерода и кислорода) на выходы продуктов его ожижения. Результаты получены на опьтно-промылиленной установке Deutsche Montan Technologie (Эссен,

Германия): производительность - 150 кг/день;

$T=465-470{ }^{\circ} \mathrm{C} ; P_{\mathrm{H} 2}=30$ МПа; катализатор («красный илам») - 1,2\% $\mathrm{Fe}_{2} \mathrm{O}_{3}$ :

$\boldsymbol{O}, \boldsymbol{\bullet}$ - содержание углерода; $\square, \boldsymbol{\square}$-содержание кислорода

daf - в пересчете на органическую массу угля (ОМУ) (по даннылм [2, 3])

Fig. 1. Effect of coal rank (content of carbon and oxygen) on its liquefaction yields. Results obtained from the process development unit of Deutsche Montan Technologie (Essen, Germany): productivity $-150 \mathrm{~kg} /$ day; $T=465-470{ }^{\circ} \mathrm{C} ; P_{\mathrm{H} 2}=$ $30 \mathrm{MPa}$; catalyst («red mud») -1,2\% $\mathrm{Fe}_{2} \mathrm{O}_{3}: \mathbf{O}, \mathbf{O}$-carbon content; $\square, \boldsymbol{\square}$ - oxygen content;

daf - calculated on the dry, ash-free basis [coal organic matter] (according to data from [2, 3])

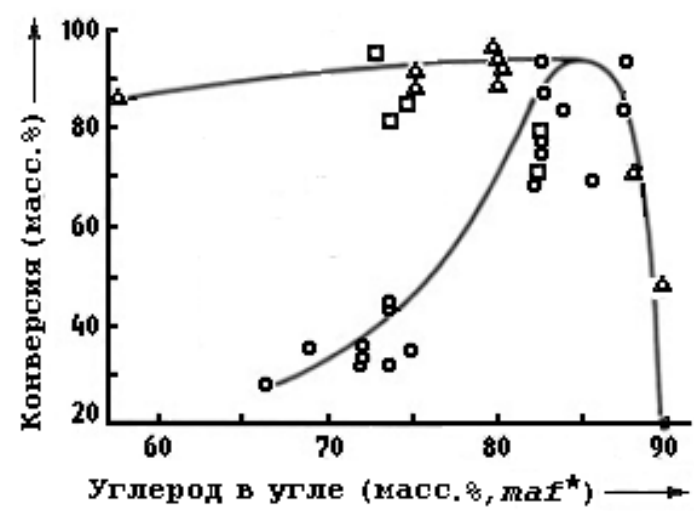

Рис. 2. Зависимость степени превращения угля от его ранга и источника водорода [4]:

O- пирен в качестве растворителя, инертная атмосфера; $\square$-пирен в качестве растворителя, атмосфера водорода; $\Delta$-тетралин-содержаший растворитель,

атмосфера водорода

*maf - в пересчете на влажный беззольный уголь Fig. 2. Dependence of conversion on coal rank and hydrogen source [4]: $\boldsymbol{O}$ - pyrene solvent, inert atmosphere; $\square$-pyrene solvent, hydrogen atmosphere; $\Delta$-tetralincontaining solvent, hydrogen atmosphere

*maf - calculated on the moisture- and ash-free basis
К настоящему времени огромный опыт, накопленный в области ожижения углей, позволяет с достаточной степенью надежности определять, какого типа или сорта угли лучше всего подвергать ожижению. На рис. 1, 2 представлены типичные зависимости степени превращения углей, а также выходов жидких и твердых продуктов от состава угольного сырья [2-4]. Как видно из этих рисунков, если содержание углерода изменяется в диапазоне $65-87 \%$, то отмечается сравнительно небольшой выход твердого органического остатка (т.е. степень конверсии в жидкие продукты довольно высокая). Максимальный выход дистиллируемых жидкостей наблюдается при содержании углерода $\sim 80-85 \%$, что соответствует битуминозным (каменным) углям [1, 5]. В то же время около $41 \%$ органического вещества битуминозного угля при ожижении не обладает заметной реакционной способностью, тогда как для лигнита количество инертного органического вещества составляет лишь 26\% [6]. Когда содержание углерода превышает 90\% (как это имеет место в случае антрацитов), то выход жидкостей вновь резко снижается. Поэтому антрацитовый уголь неэкономично использовать для процесса DCL.

В случае углей с содержанием углерода $65-80 \%$, что характерно для низкосортных углей, а также для лигнина или древесины, наблюдается достаточно высокая степень конверсии вследствие повышенного содержания кислорода ( 15-30\%). При этом количество дистиллируемых жидких продуктов снижается, а таких продуктов, как $\mathrm{CO}, \mathrm{CO}_{2}$ и $\mathrm{H}_{2} \mathrm{O}$, наоборот, возрастает, что объясняет больший расход водорода при переработке низкосортных углей. $\mathrm{C}$ другой стороны, низкосортные угли более чувствительны к концентрации Ндонора в составе растворителя и 


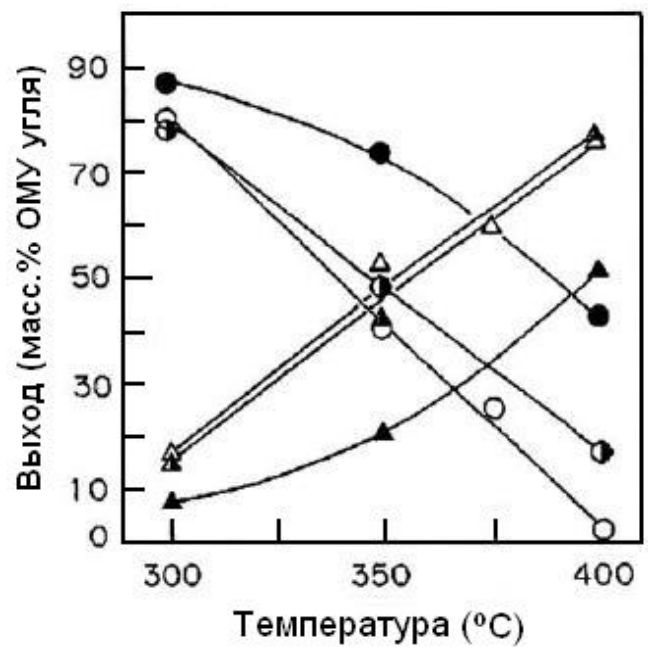

Рис. 3. Температурные зависимости выходов неэкстрагируемого остатка (-, (-) О) и растворимой в тетрагидрофуране фракции с т.к. $>350{ }^{\circ} \mathrm{C}$, содержащей мальтены, асфальтены и преасфальтены $(\boldsymbol{\Lambda}, \mathbf{\Lambda}, \Delta)$, от степени метаморфизма ожижаемых углей: битуминозный уголь Datong $(\boldsymbol{O}, \boldsymbol{\Lambda})$; суббитуминозный

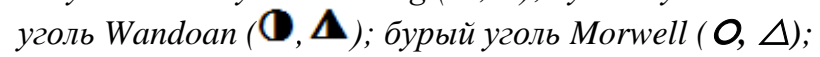
время реакиии 2 ч [13]

Fig. 3. Temperature dependences of yields of non-extractable residue $(\boldsymbol{O}, \mathbf{0}, \mathbf{O})$ and a tetrahydrofurane soluble distillate fraction containing maltenes, asphaltenes and preasphaltenes $(\boldsymbol{\Lambda}, \boldsymbol{\Lambda}, \Delta)$ on coal rank of liquefied coals: bituminous coal Datong (, $\mathbf{\Lambda})$; subbitiminous coal Wandoan (- $\mathbf{\Lambda})$; brown coal Morwell $(\mathbf{O}, \Delta)$; reaction time $2 \mathrm{~h}$ [13] требуют более жестких условий реакции для достижения максимального выхода жидких продуктов. Тем не менее, в целом отмечается увеличение степени конверсии углей при понижении степени их метаморфизма, причем в достаточно широком интервале температур $\left(300-475^{\circ} \mathrm{C}\right) \quad[5, \quad 7]$. Несмотря на то, что угли с низкой степенью метаморфизма (лигниты, бурые и полубитуминозные угли) ожижаются легче, выход углеводородов при их конверсии весьма ограничен вследствие повышенного содержания в их составе кислорода, который, как было сказано выше, при термообработке образует воду и оксиды углерода [3]. Хотя общий выход углеводородов имеет тенденцию к уменьшению с понижением ранга углей, доля низкокипящих дистиллятов при этом увеличивается; в частности, жидкие продукты переработки суббитуминозных углей более летучи, содержат больше насыщенных углеводородов, менее ароматичны, имеют более высокое содержание водорода и значительно меньшее содержание гетероатомов, чем аналогичные продукты ожижения битуминозных углей [8]. Отмечается также [1], что существенный вклад в достаточно высокую ожижаемость низкометаморфизованных углей могут вносить присутствующие в их составе низкомолекулярные смолистые вещества, обогащенные водородом, которые в процессе ожижения могут служить Н-донорами и растворителями для крупных молекулярных фрагментов углей.

Но, с другой стороны, ожижение углей низкого сорта создает определенные трудности с перекачкой жидкостей из-за высокой вязкости остаточных продуктов. Высокая вязкость образующихся при ожижении флюидов может быть связана как с кислородным сшиванием, что характерно для низкосортных углей с высоким содержанием кислорода, так и с недостаточным поступлением энергии, необходимой для разрыва связей [1]. Эту проблему можно частично решить, увеличивая продолжительность ожижения [9] или добавляя в загрузочную шихту катализаторы одноразового действия. Как было отмечено ранее [10], по сравнению с типичными каменными углями низкосортные угли содержат меньше серы, больше влаги и больше органического кислорода. Высокое содержание кислорода объясняет отсутствие у этих углей пластических свойств, что исключает механизмы ожижения, характерные для каменных углей [11]. Кроме того, присутствие в низкосортных углях соединений Са (например, в виде солей гуминовой кислоты) составляет до 3 масс.\%. Эти соединения в процессе ожижения превращаются в $\mathrm{CaO}$ и вступают в реакцию с $\mathrm{CO}_{2}$, что приводит к отложению $\mathrm{CaCO}_{3}$ на стенках реактора. Накопление и отложение карбоната кальция можно предотвратить периодическим удалением твердых частиц из реактора или предварительной обработкой угля газообразным диоксидом серы, поскольку отложения не образуются из стабильных солей кальция, таких как сульфат кальция. Перечисленные выше недостатки, связанные с 
Таблица 1. Сравнение выходов продуктов ожижения высоководородного арктического угля Свальбард (Шпицберген, Норвегия) с аналогичными показателями для каменных углей США (Иллинойс № 6) и Великобритании (Лонганнет) [17]

Table 1. Comparison of liquefaction yields obtained during thermal treatment of Arctic perhydrous Svalbard coal (Spitsbergen, Norway) with those produced for USA

(Illinois no. 6) and UK (Longannet) bituminous coals [17]

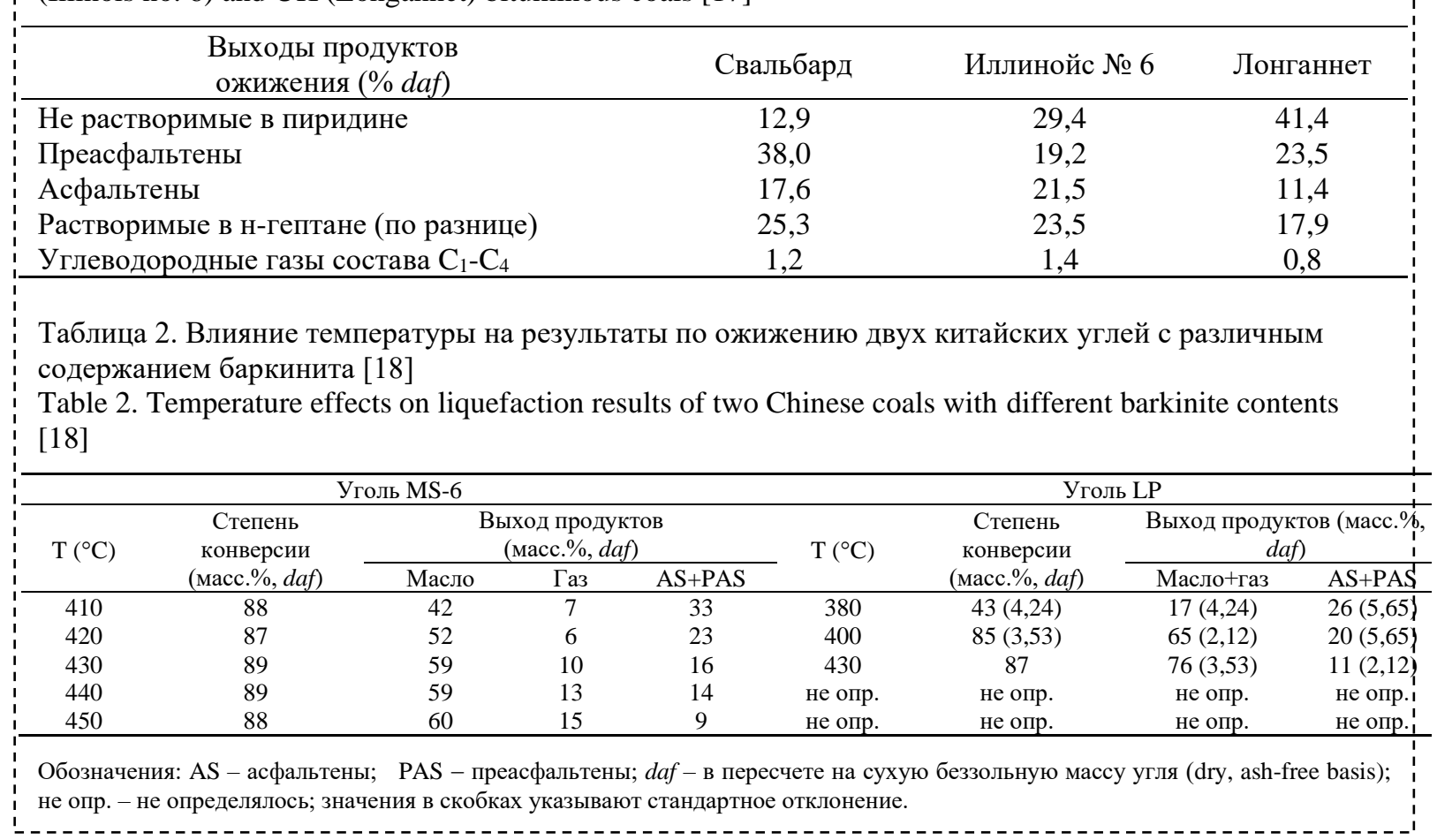

переработкой низкосортных углей, являются одной из причин того, что данные угли во многих случаях не рассматриваются в качестве привлекательного сырья для процессов ожижения [1].

Необходимо также отметить, что при изучении влияния степени метаморфизма углей на их ожижаемость следует обращать особое внимание на показатели зольности перерабатываемых углей, поскольку при ожижении высокозольных суббитуминозных и бурых углей степени конверсии и выходы жидких продуктов обычно ниже аналогичных показателей низкозольных битуминозных (каменных) углей [12].

Кабе и сотр. [13] обнаружили, что независимо от степени метаморфизма углей реакция их водородного обмена с газообразным водородом протекает уже при $300^{\circ} \mathrm{C}$, а ее интенсивность быстро возрастает с повышением температуры от 350 до $400^{\circ} \mathrm{C}$. Коэффициент водородного обмена увеличивается в ряду: битуминозный уголь < суббитуминозный уголь < бурый уголь. При этом выходы угольных жидкостей увеличиваются с повышением температуры, а степени превращения угольного сырья уменьшаются с ростом степени метаморфизма углей (рис. 3).

Несмотря на многочисленные сведения о взаимосвязи ожижаемости углей со степенью их метаморфизма, уже в относительно ранней публикации [14] на основании статистической обработки данных по ожижению в присутствии тетралина 68-и различных углей (в стандартных условиях, но без добавления катализатора или молекулярного водорода) был сделан вывод о том, что попытки построения линейных корреляций ожижаемости угля только с таким параметром степени метаморфизма, как содержание углерода, не могут считаться адекватными. Для получения более или менее удовлетворительных результатов по прогнозу ожижаемости угля необходимо учитывать, по крайней мере, три различные характеристики угля [14].

Важную роль при этом играют условия ожижения угля: если процесс протекает в относительно мягких условиях (т. е. при небольших временах контакта), зависимость степени превращения углей от их характеристик достаточно заметна, но эти различия, как правило, менее очевидны с увеличением жесткости условий проведения данного процесса [15]. 


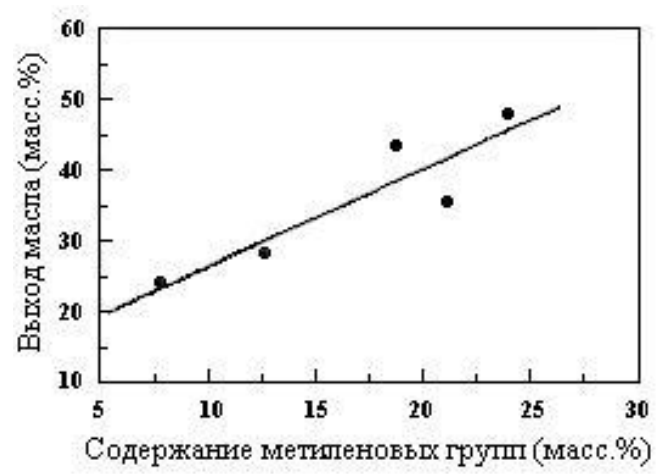

Рис. 4. Корреляция между выходом масла и содержанием $\mathrm{CH}_{2}$-групп в угле при его ожижении [19]

Fig. 4. Correlation between yield of oil and $\mathrm{CH}_{2}$ group content in coal during its liquefaction [19]

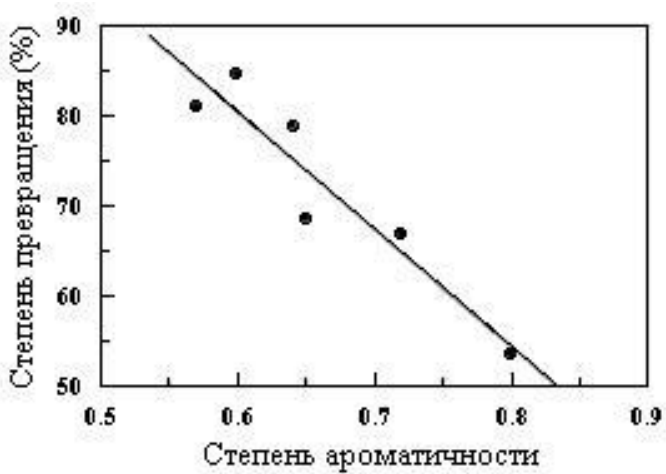

Рис. 5. Взаимосвязь степени ароматичности угля со степенью его превращения в процессе ожижения [19]

Fig. 5. Relationship of coal aromaticity with its conversion during the liquefaction process [19]

Активность в реакции гидроожижения достаточно хорошо коррелирует с количеством водорода, выделяющегося в ходе пиролиза углей при атмосферном давлении, но еще лучше эта корреляция наблюдается между активностью углей в процессах ожижения и содержанием в них атомов алифатического водорода $\left(\mathrm{H}_{\mathrm{al}}\right)$ [16, с. 193].

C точки зрения максимизации выхода жидких продуктов, а также минимизации потребления водорода значительный интерес представляют угли, богатые водородом, или высоководородные угли. Такие угли либо богаты липтинитом, либо содержат богатый водородом деградированный витринит, формирующийся вследствие поступления в состав углей бактериального вещества [17]. Результаты, представленные в табл. 1, показывают, что как общая степень превращения в пиридин- и толуолрастворимые продукты, так и выход масла (мальтенов), при переработке высоководородного угля (Свальбард) в присутствии водорододонорного растворителя оказываются выше, чем в случае типичных каменных углей [17].

К высоководородным углям относятся и позднепермские ко́ровые угли Южного Китая (угольный бассейн Лепин, провинция Цзянси, КНР), характеризующиеся повышенным содержанием так называемого баркинита ${ }^{1}$ [18]. Наиболее интересный температурный диапазон для термопереработки баркинита составляет $410-450^{\circ} \mathrm{C}$ : температуры максимальной потери летучих веществ в обогащенных баркинитом углях находятся в именно этом температурном диапазоне, максимальная текучесть наблюдается при $T \sim 440^{\circ} \mathrm{C}$, а размер частиц резко уменьшается при нагревании до $T \sim 430^{\circ} \mathrm{C}$ или выше. При ожижении ко́рового угля (LP) в температурном интервале $410-450^{\circ} \mathrm{C}$ наблюдаются почти такие же значения степени конверсии, как и для угля (MS-6) с относительно низким содержанием баркинита, но при этом выходы масла и газа, а также выход суммы преасфальтенов и асфальтенов явно зависят от температуры, и для угля LP выходы масла и газа заметно выше (табл. 2) [18].

В ходе ожижения углей, элементный состав которых обогащен водородом, Ванг и сотр. [19] обнаружили, что существует практически линейная зависимость между выходом масла и содержанием $\mathrm{CH}_{2}$-групп в исследуемых углях (рис. 4). Аналогичный результат ранее был получен Йошидой и сотр. [20]. При этом наблюдалась антибатная зависимость между степенью конверсии образцов исследуемых углей и их ароматичностью (рис. 5), т. е. чем выше степень ароматичности образца угля, тем ниже степень его превращения [19]. Это означает, что значительная часть ароматических групп в образцах высокоароматичных углей не подвергалась

\footnotetext{
${ }^{1}$ Баркинит считается мацералом из группы липтинита (экзинита), полученным из перидермы или коры высших растений, у которых клеточная стенка и наполняющий материал, по-видимому, пропитались смолой или суберином [18]. Хотя баркинит часто идентифицируется как суберинит или кутинит, он сам имеет особые петрографические характеристики. Для обогащенных баркинитом углей характерным является более высокое содержание водорода $\left(\mathrm{H}^{d a f}>6\right.$ масс.\%) и летучих веществ ( $V^{d a f}$ до 56-57 масс.\%) по сравнению с другими углями аналогичного сорта [18, 19].
} 


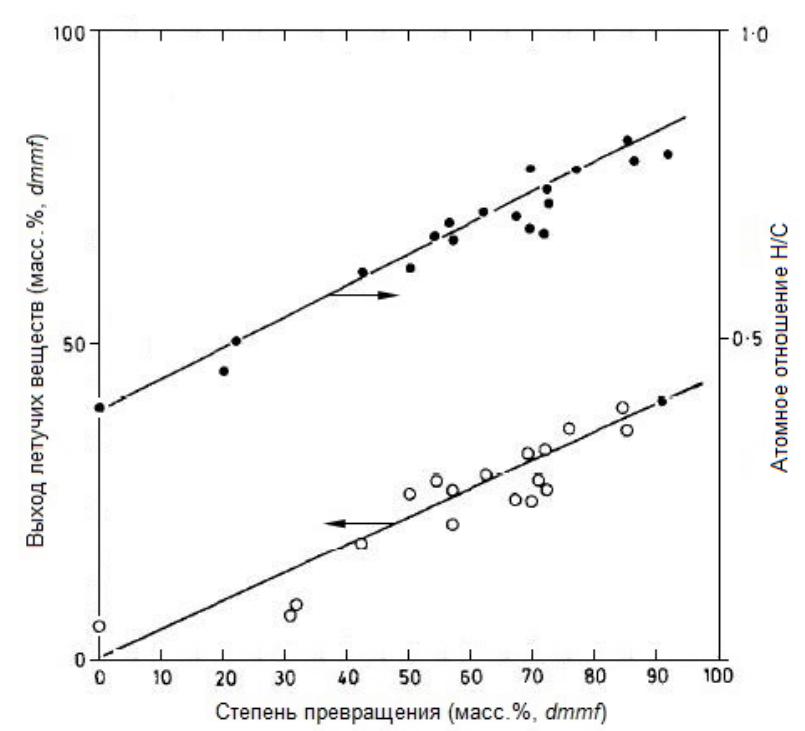

Рис. 6. Изменение степени превращения каменного угля в зависимости от атомного

отношения H/С и содержания в нем летучих веществ при гидрировании угля

в автоклаве в присутствии антраценового масла ( $T=$ $450^{\circ} \mathrm{C} ; \mathrm{P}=25 \mathrm{M \Pi а}$;

антраценовое масло/уголь = 3:1); [Степень превращения $=202 \cdot(H / C)-78][23]$

Fig. 6. Variation in coal conversion depending on the $H / C$ atomic ratio and content of volatile matter in it during coal hydrogenation in an autoclave in the presence of anthracene oil

$\left(T=450{ }^{\circ} \mathrm{C} ; P=25 \mathrm{MPa} ;\right.$ anthracene oil/coal $\left.=3: 1\right)$; [Conversion $=202 \cdot(\mathrm{H} / \mathrm{C})-78][23]$ конверсии при выбранных условиях ожижения $\left(\mathrm{T} \sim 430^{\circ} \mathrm{C}, \mathrm{P}_{\mathrm{H} 2}=6.9 \mathrm{MПа}\right.$, тетралин/уголь $=3: 1$, катализатор $\mathrm{FeS}_{2}$ ).

Если рассматривать выходы отгоняемых жидких продуктов, а не общие степени конверсии, то могут быть установлены вполне удовлетворительные корреляции с атомными отношениями $\mathrm{H} / \mathrm{C}$ в ожижаемых углях [21]. Например, во многих работах [16, 22-24] приводятся достаточно убедительные доказательства наличия взаимосвязи между выходами продуктов ожижения углей и соотношениями в них углерода и водорода (атомными отношениями Н/C). Аналогичные корреляции наблюдаются между ожижаемостью углей и содержанием в них летучих веществ $\left(\mathrm{V}^{d a f}\right)$. В частности, с ростом значений Н/C и $\mathrm{V}^{\text {daf }}$ реакционная способность углей в процессах ожижения быстро возрастает. На рис. 6 показаны изменения степени превращения угля в реакции его гидрирования в присутствии антраценового масла в зависимости от атомного отношения H/C и содержания летучих веществ в этом угле. Были получены хорошие корреляции, причем коэффициенты

корреляции для линейных регрессионных зависимостей были порядка 0,96 [23]. Интересно отметить, что наклон линий регрессии (см. рис. 6) очень похож как при гидрировании угля в отсутствие растворителя, так и при конверсии угля в присутствии растворителя (антраценового масла). Этот факт может указывать на то, что термическая фрагментация угля является важнейшим шагом в каждом из этих режимов осуществления процесса, и что основное различие здесь заключается лишь в способе стабилизации образующихся термических фрагментов [23]. Однако, по данным Марко и др. [24], хорошая линейная корреляция имеет место только между степенью конверсии и соотношением Н/C, в то время как связь между степенью превращения и содержанием летучих веществ $\left(V^{d a f}\right)$, вероятно, лучше выражается криволинейной зависимостью. Установлено [25], что для углей с соотношением Н/C = 0,7 и выше степень конверсии превышает 50\%, а при соотношениях $\mathrm{H} / \mathrm{C}=0,6$ и ниже степень превращения составляет менее 30\%.

При этом хорошая корреляция ожижаемости углей и содержания в них летучих веществ наблюдается далеко не всегда. Дело в том, что измеряемое летучее вещество угля ( $\left.V^{d a f}\right)$ включает в себя не только летучие органические продукты, но также и неорганические материалы, такие как минеральные вещества угля, остатки катализатора ожижения, а также некоторые побочные продукты, образующиеся при приготовлении катализатора [26]. Поэтому выход летучих веществ, измеренный стандартным техническим анализом (при нагреве угля до $930^{\circ} \mathrm{C}$ ), правильнее называть «суммарным летучим веществом» (total volatile matter или TVM), которое не отражает органические свойства исследуемого остатка ожижения, как это можно было бы ожидать для $V^{d a f}$. 
В связи с этим некоторые авторы [26] в качестве показателя $V^{d a f}$ рекомендуют использовать выход летучих веществ, выделяющихся в интервале температур от 110 до $700^{\circ} \mathrm{C}$, т. е. использовать параметр, который можно было бы назвать органическим $V^{d a f}$. Данный параметр показывает лучшую линейную корреляцию с атомным отношением H/C в углеродном остатке и более адекватно характеризует реакционную способность этого остатка, чем показатель TVM [26].

Важным фактором, влияющим на зависимость ожижаемости углей от их химического состава, является также присутствие в реакционной системе катализатора. Некаталитические и каталитические эксперименты по ожижению ряда различных углей (от суббитуминозного типа В до легколетучих битуминозных типа А) в микроавтоклавах $\left(\mathrm{T}=360^{\circ} \mathrm{C}, \mathrm{t}=1\right.$ ч) в атмосфере водорода с использованием неводорододонорного растворителя (фенантрена) показали [27], что в некаталитических реакциях степень конверсии варьировалась в пределах от 18 до 47\%; при этом наблюдалась ее явная зависимость от содержания кислорода в углях. Добавление катализатора увеличивало степень превращения углей до $54-83 \%$, но при этом в каталитических реакциях не наблюдалось явной зависимости степени конверсии от содержания кислорода. Здесь более важными показателями были общее содержание водорода, а также концентрация «чистого» водорода (т. е. количество общего водорода с поправкой на кислород, серу и азот) и его распределение в структуре угля [27].

\section{Влияние петрографического состава углей}

Петрографические компоненты (мащераль) группы витринита и липтинита (экзинита), присутствующие в суббитуминозных и битуминозных углях (доля этих компонентов для большинства углей превышает 80 об.\% от органического состава), обычно считаются наиболее реакционноспособными материалами, подвергающимися быстрым реакциям фрагментации и являющимися основными прекурсорами жидких продуктов в ходе термической переработки угольного сырья; мацералы типа инертинита, характеризующиеся более низкими значениями атомных отношений $\mathrm{H} / \mathrm{C}$, за некоторыми исключениями гораздо менее реакционноспособны [1, $2,5]$. Установлено, что содержание реакционноспособных мацералов коррелирует со степенью конверсии углей одного класса, что подтверждается для однотипных углей из целого ряда различных геологических регионов. Такие компоненты группы инертинита, как полуфюзинит и фюзинит, производят незначительные количества жидких продуктов, но могут действовать как зародыши для образования кокса, что может быть вредным для окончательного превращения угля в жидкость [28]. Низкая активность инертинита связана с глубокими превращениями, которым подверглась исходная древесина в ходе формирования данного ингредиента [16]. Однако инертинит, присутствующий в небитуминозных углях Южного полушария, особенно мацеральный полуфюзинит, обладающий низкой отражательной способностью, может вносить значительный вклад в их общую конверсию, и гораздо лучшие корреляции достигаются, если рассматривать присутствующий в этих углях полуфюзинит как реакционноспособный мацерал $[29,30]$. Участие некоторых мацералов группы инертинита в процессе ожижения наблюдалось также и при изучении конверсии угля месторождения Daheb (провинция Гуйчжоу, KHP) [31].

В работе [32] изучено прямое ожижение концентратов витринита из углей шахт Cerrejon и Jagua (Колумбия, Южная Америка). Концентраты витринита получали колонной флотацией при $\mathrm{pH} 7$, скорости воздуха 1,4 см/с и концентрации вспенивателя 4 мл/кг угля. Эксперименты проводились при 380,400 и $420^{\circ} \mathrm{C}$ с разбавлением растворителем-донором водорода (тетралином) при продолжительности ожижения $~ 30$ мин с использованием следующих соотношений тетралин/уголь: 2:1, 2,5:1 и 3:1. Было установлено, что степени конверсии у выделенных концентратов витринита, как правило, были выше, чем степени конверсии, наблюдаемые для исходных углей. Результаты показали, что степень конверсии имеет тенденцию к возрастанию с повышением температуры, а также с увеличением отношения тетралин/уголь. Выходы фракций масла и газа также увеличивались с ростом температуры и соотношения тетралин/уголь, тогда как для выходов остатка наблюдалась противоположная зависимость [32]. 
Каталитическое гидроожижение двух углей (Freyming, Франция и Point of Ayr, Великобритания), а также их петрографических компонентов было изучено в микроавтоклаве в присутствии Н-донорного растворителя (тетралина) [33]. Сопоставлено поведение данных углей и их мацералов в процессе гидроожижения; при этом оба угля показали одинаковую степень общей конверсии и одинаковые выходы фракций масла, асфальтенов и преасфальтенов. Кроме того, изучен вклад каждого мацерала в суммарный выход «угольной жидкости»; показано, что исходные угли, а также витринит и экзинит (липтинит) имели примерно одинаковые значения степени общей конверсии, но степень превращения фюзинита была намного ниже [33].

\section{Влияние минеральной части углей}

Минералы в угле часто рассматриваются как нежелательная примесь, являющаяся причиной большинства проблем, возникающих в процессе утилизации угля, но в некоторых случаях минералы могут также оказывать благотворное влияние на ожижение угля [34]. Минеральное вещество следует отличать от золы. Зола является неорганическим остатком, полученным в результате сжигания угля, и, следовательно, в основном представляет собой смесь неорганических оксидов, образующихся в результате пиролиза и окисления минерального вещества. Хотя разновидностей минеральных веществ в угле довольно много, и они включают в себя огромное количество микроэлементов, наиболее распространенными минералами, присутствующими в углях, являются кварц $\left(\alpha-\mathrm{SiO}_{2}\right)$, глины (смесь минералов группы каолинита, монтмориллонита и других слоистых алюмосиликатов), мусковит (пластинчатый калийсодержащий алюмосиликат), полевые шпаты (алюмосиликаты каркасного типа, включающие оксиды щелочных и щелочноземельных элементов), пирит $\left(\mathrm{FeS}_{2}\right)$ и карбонаты: сидерит $\left(\mathrm{FeCO}_{3}\right)$, кальцит $\left(\mathrm{CaCO}_{3}\right)$ и доломит $\left[\mathrm{CaMg}\left(\mathrm{CO}_{3}\right)_{2}\right][5,34,35]$.

В ходе термической конверсии углей входящие в их состав минеральные вещества могут выступать как в качестве катализаторов \{например, каолинит $\left[\mathrm{Al}_{2} \mathrm{Si}_{2} \mathrm{O}_{5}(\mathrm{OH})_{4}\right]$, способствующий превращению угля в газообразные и растворимые в бензоле соединения $\}$, так и в качестве ингибиторов процессов ожижения (в случае, когда минеральные компоненты закупоривают поры катализатора и образуют отложения в реакторах) [5, 36, 37]. Железо и титан, содержащиеся в угле, оказывают каталитическое воздействие на его гидрирование, увеличивая степень конверсии, а пиритная и органическая сера, присутствующая в угле, по-видимому, ответственна за формирование каталитически наиболее активной в ожижении нестехиометрической формы сульфида железа - пирротина $\left(\mathrm{Fe}_{1-\mathrm{x}} \mathrm{S}\right)$, который образуется из железа, содержащегося в минеральном веществе угля [37]. Помимо этого, железосодержащие минералы (например, пирит) способны катализировать не только реакции гидрирования углей, но и реакции гидрирования, обессеривания и деазотирования продуктов их ожижения [38-40].

Предполагается, что механизмы, описывающие каталитическую активность $\mathrm{FeS}_{2}$ в атмосфере $\mathrm{H}_{2}$, включают целую серию последовательных реакций, но не прямую реакцию $\mathrm{H}_{2} \mathrm{c}$ $\mathrm{FeS}_{2}$, и один из таких возможных механизмов может быть представлен следующим образом [39]:

$$
\begin{aligned}
\mathrm{FeS}_{2} & \rightarrow \mathrm{FeS}+\mathrm{S} \\
\mathrm{S}+\mathrm{H}_{2} & \rightarrow \mathrm{H}^{\bullet}+\mathrm{HS}^{\bullet} \\
\mathrm{HS}^{\bullet}+\mathrm{H}_{2} & \rightarrow \mathrm{H}_{2} \mathrm{~S}+\mathrm{H}^{\bullet}
\end{aligned}
$$

С увеличением содержания глинистых материалов (в частности каолина) в структуре угля степень его превращения быстро возрастает (рис. 7); но одновременно с этим глинистые минералы ускоряют реакции ароматизации, конденсации и коксообразования продуктов ожижения $[37,39]$, и, следовательно, такие минеральные компоненты неблагоприятны для генерации масла [39]. 
В эксперименте по ожижению двух высокосернистых углей было обнаружено [41], что после предварительной обработки углей $\mathrm{HNO}_{3}$ (для удаления пирита) общая степень конверсии и суммарный выход масла и газа значительно уменьшались; это убедительно подтверждает каталитическую роль пирита в процессах прямого ожижения углей. Кроме того, данное исследование также показало, что пирит может влиять на процесс регидрирования растворителя. В отсутствие пирита растворитель склонен подвергаться дегидрированию, и распределение образующихся продуктов ожижения имеет тенденцию смещаться в сторону образования более высокомолекулярных компонентов [41].

В составе минеральной части бурых углей значительную долю занимают кальций- и железосодержащие соединения. Результаты экспериментов показывают, что добавление $\mathrm{CaO}$ и $\mathrm{Fe}_{2} \mathrm{O}_{3}$ оказывает каталитическое влияние на пиролиз углей. Так, выход угля и газа заметно увеличивались при добавлении этих оксидов, а выход смолы сначала увеличивался, а затем уменьшался. Наибольший каталитический эффект в процессе пиролиза угля достигался при добавлении 1,5 масс.\% $\mathrm{Fe}_{2} \mathrm{O}_{3}$ или 0,5 масс.\% $\mathrm{CaO}$ [42].

Обнаружено [43], что в низкозольных лигнитах с повышением содержания золы (т. е. с ростом количества минеральных компонентов), как правило, возрастают как общая степень конверсии угля, так и степень его превращения в вещества, растворимые в тетрагидрофуране (ТГФ), толуоле или $\boldsymbol{t}$-гексане. В то же время для высокозольных углей изменение содержания золы, по-видимому, не оказывает влияния на общую степень конверсии угля и выходы веществ, растворимых в ТГФ и толуоле.

Каталитическая активность минеральных компонентов угля в процессе его ожижения зависит не только от концентрации в нем минерального вещества, но и от того, в какой форме активные минеральные компоненты угля присутствуют в его составе. Так, ионы $\mathrm{Ca}^{2+}$, присутствующие в угле в ионообменной форме, ускоряют образование фрагментов $\mathrm{CO}_{2}$ и свободных радикалов на стадии пиролиза угольного вещества, что усиливает дисбаланс между скоростью образования свободных радикалов и их взаимодействием с донорами водорода; это увеличивает количество высокомолекулярных (не растворимых тетрагидрофуране) соединений, что в конечном счете приводит к снижению выхода продуктов ожижения [44]. При

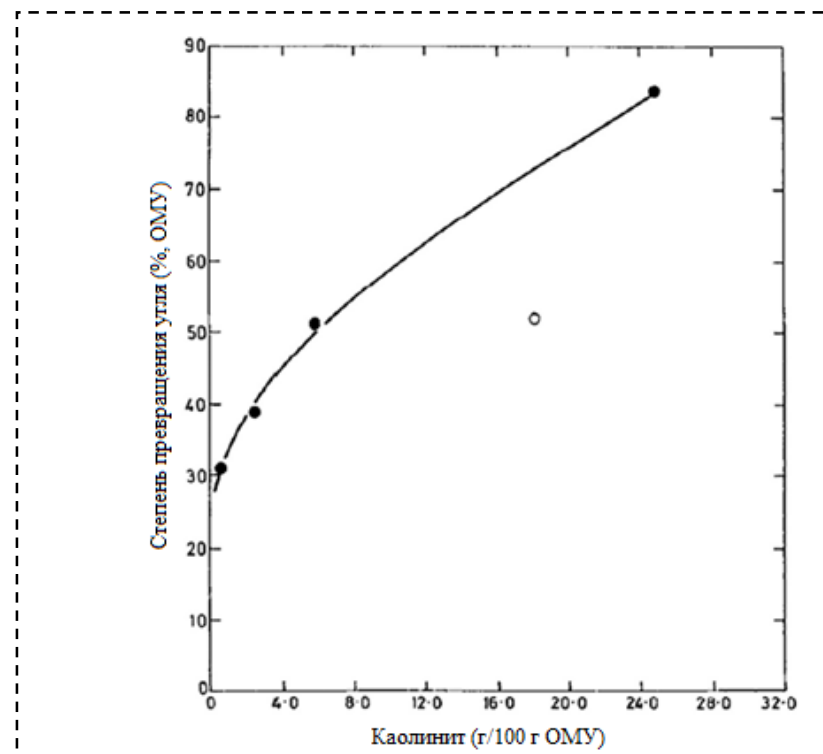

Рис. 7. Изменение степени превращееня угля от содержания в нем каолинита:

O- фракция деминерализованного угля плотностью 1,3 г/см ${ }^{3}$ с нанесеннылм каолинитом [37, 39]

Fig. 7. Change of coal conversion with kaolinite content: $\boldsymbol{O}$ kaolin impregnated

on 1.3 sp. gr. fraction of demineralized coal [37, 39] этом ингибирующее воздействие на ожижение углей ионов $\mathrm{Ca}^{2+}$ в составе отдельных солей или минералов практически отсутствует [44]. С другой стороны, активность ионов $\mathrm{Fe}^{2+}, \mathrm{Co}^{2+}$ и $\mathrm{Ni}^{2+}$, введенных в состав суббитуминозного угля методом ионного обмена, в процессе его ожижения была значительно выше активности данных ионов в составе оксидов, сульфидов или маслорастворимых комплексов (металлоценов или карбонилов) [45].

При термической конверсии низкометаморфизованных твердых топлив (бурых и сапропелитовых углей, а также горючих сланцев), характеризующихся довольно высоким содержанием кислорода, важную роль играют каталитические процессы превращения кислородсодержащих функциональных

групп, протекающие под воздействием минерального вещества угля. Установлено [46], что катионы 
металлов, входящие в состав минеральных компонентов углей, катализируют разложение карбоксильных димеров и таким образом способствуют образованию ангидридов и сложных эфиров типа RCOOAr. Глины и кварц, в свою очередь, тормозят удаление карбоновых кислот и их производных из реакционной зоны, препятствуя диффузии летучих веществ в окружающую атмосферу; эти минералы также подавляют образование RCOOAr, поскольку они препятствуют контактам между кислородсодержащими функциональными группами [46].

\section{Заключение}

Характеристики исходного угольного сырья, такие как ранг угля (степень углефикации), петрографический состав и минеральные компоненты, оказывают огромное влияние на выход и свойства продуктов, образующихся при ожижении твердых топлив. Выход жидких продуктов зависит от класса используемого угля и содержания в нем углерода. Максимальный выход дистиллируемых жидкостей наблюдается при содержании углерода $\sim 80-85 \%$, что соответствует битуминозным (каменным) углям. В случае низкосортных углей (лигнитов, сапропелитов, горючих сланцев и других твердых топлив) наблюдается достаточно высокая степень конверсии вследствие повышенного содержания кислорода ( 15-30\%), но при этом количество дистиллируемых жидких продуктов снижается, а таких продуктов, как $\mathrm{CO}, \mathrm{CO}_{2}$ и $\mathrm{H}_{2} \mathrm{O}$, наоборот, возрастает. Имеются данные о наличии практически линейной зависимости между выходом масла и содержанием $\mathrm{CH}_{2}$-групп в ожижаемых углях, в то время как обратная зависимость наблюдается между степенью конверсии углей и их ароматичностью. Получены достаточно убедительные доказательства наличия взаимосвязи между выходами продуктов ожижения углей и соотношениями в них углерода и водорода (атомными отношениями Н/C). Аналогичные корреляции наблюдаются между ожижаемостью углей и содержанием в них летучих веществ $\left(V^{d a f}\right)$. Так, с ростом значений $\mathrm{H} / \mathrm{C}$ и $V^{d a f}$ реакционная способность углей в процессах ожижения быстро возрастает.

Среди петрографических компонентов углей наиболее реакционноспособными материалами, Мацералы типа инертинита, подвергающимися быстрым реакциям фрагментации, являются витринит и экзинит (липтинит), характеризующиеся более низкими значениями атомных отношений $\mathrm{H} / \mathrm{C}$, за некоторыми исключениями гораздо менее реакционноспособны.

Минеральные вещества, входящие в состав углей (силикаты, глины, пирит, карбонаты и др.), могут выступать как в качестве катализаторов, так и в качестве ингибиторов процессов ожижения. Так, железосодержащие минералы способствуют реакциям гидрирования и крекинга угольного вещества, а также продуктов его превращений. Наличие в составе угля глинистых материалов (например, каолина) приводит к увеличению степени его превращения, но одновременно с этим глинистые минералы ускоряют реакции ароматизации, конденсации и коксообразования продуктов ожижения. В низкозольных углях с повышением содержания золы (т. е. с увеличением количества минеральных компонентов), как правило, возрастают как общая степень конверсии угля, так и выход жидких продуктов, но в высокозольных углях изменение содержания золы, по-видимому, не влияет на общую степень конверсии органической массы угля и выходы веществ, растворимых в ТГФ и толуоле. Каталитическая активность минеральных компонентов угля в процессе его ожижения зависит не только от концентрации в нем минерального вещества, но и от того, в какой форме активные минеральные компоненты угля присутствуют в его составе (в ионообменной форме или в составе отдельных солей или минералов).

\section{СПИСОК ЛИТЕРАТУРЫ}

1. Kaneko T., Derbyshire F., Makino E., Gray D., M. Tamura M. Coal Liquefaction // Ullmann's Encyclopedia of Industrial Chemistry. V. 9. - Weinheim (Germany): Wiley-VCH, 2012. - P. 311-389. 
2. Burgess Clifford C., Song C.. Direct Liquefaction (DCL) Processes and Technology for Coal and Biomass Conversion. Science and Technology // Advances in Clean Hydrocarbon Fuel Processing. - New Delhi (India): Woodhead Publ. Ltd., 2011. - P. 105-154.

3. Van Heek K H, Strobel B O, Wanzl W. Coal Utilization Processes and Their Application to Waste Recycling and Biomass Conversion // Fuel. - 1994. - V. 73. - N 7. - P. 1135-1143.

4. Derbyshire F.J., Whitehurst D.D. Study of Coal Conversion in Polycondensed Aromatic compounds // Fuel. - 1981. - V. 60. - N 8. - P. 655-662.

5. Haenel M.W. Catalysis in Direct Coal Liquefaction // Handbook of Heterogeneous Catalysis. V. 6. Energy-Related Catalysis (G. Ertl, H. Knözinger, F. Schüth and J. Weitkamp, Eds.). $2^{\text {nd }}$ Edition. Weinheim (Germany): Wiley-VCH, 2008. - P. 3023-3036.

6. Rosal R., Diez F.V., Sastre H. Hydrogen-Transferring Liquefaction of Two Different Rank Coals Employing Hydrogenated Anthracene Oil as a Donor Solvent // Ind. \& Eng. Chem. Res. - 1992. - V. 31. - P. 2407-2412.

7. Snape C.E., Derbyshire F.J., Stephens H.P., Kottenstette R.J., Smith N.W. Influence of Organic Coal Structure on Liquefaction Behaviour: An Update with Emphasis on Low Severity Conditions // Fuel Process. Technol. - 1990. - V. 24. - P. 119-125.

8. Vasireddy S., Morreale B., Cugini A., Song C., Spivey J.J. Clean Liquid Fuels from Direct Coal Liquefaction: Chemistry, Catalysis, Technological Status and Challenges // Energy \& Environ. Sci. - 2011. - V. 4. - N 2. - P. 311-345.

9. Neavel R.C. Exxon Donor Solvent Liquefaction Process // Philos. Trans. R. Soc. London. Ser. A, 1981. - V. 300. - N 1353. - P. 141-156.

10.Петров И.Я., Ушаков К.Ю., Богомолов А.Р., Трясунов Б.Г. Каталитическое ожижение углей перспективный способ производства моторных топлив и ценных химических соединений. Часть 2. Структура углей и химизм процессов их прямого ожижения // Вестник Кузбасского государственного технического университета. - 2020. - № 5 (141). - С. 33-46.

11.Neavel R.C. Coal Plasticity Mechanism: Inferences from Liquefaction Studies // Coal Science (M. L. Gorbaty, J.W. Larsen, and J. Wender, Eds.). V. 1. - New York: Academic Press, 1982. - P. 1-19.

12.Lee J.M., Cantrell C.E. Effect of Coal Rank and Quality on Two-Stage Liquefaction // Fuel Process. Technol. - 1991. - V. 29. - N 3. - P. 171-197.

13.Kabe T., Horimatsu T., Ishihara A., Kameyama H., Yamamoto K. Tritium as a Tracer in Coal Liquefaction. 4. Hydrogen-Exchange Reactions between Hydrogen in Coals and Tritiated Hydrogen Molecule // Energy \& Fuels. - 1991. - V. 5. - N 3. - P. 459-463.

14.Abdel-Baset M.B., Yarzab R.F., Given P.H. Dependence of Coal Liquefaction Behaviour on Coal Characteristics. 3. Statistical Correlations of Conversion in Coal-Tetralin Interactions // Fuel. - 1978. - V. 57. N 2. - P. 89-94.

15.Snape C.E. Characterisation of Organic Coal Structure for Liquefaction // Fuel Process. Technol. 1987. - V. 15. - P. 257-279.

16.Липович В. Г., Калабин Г. А., Калечиц И. В. и др. Химия и переработка угля (под ред. В.Г. Липовича). - М.: Химия, 1988. - 336 с.

17.Marshall C., Large D.J., Meredith W., Snape C.E., Uguna C., Spiro B.F., Orheim A., Jochmann M., Mokogwu I., Wang Y., Friis B. Geochemistry and Petrology of Palaeocene Coals from Spitzbergen - Part 1: Oil Potential and Depositional Environment // J. Coal Geol. - 2015. - V. 143. - P. 22-33.

18.Wang S., Tang Y., Schobert H.H., Jiang D., Sun Y., Guo Y., Su Y., Yang S. Application and Thermal Properties of Hydrogen-Rich Bark Coal // Fuel. - 2015. - V. 162. - P. 121-127.

19. Wang S., Tang Y., Schobert H.H., Guo Q., Wang F. Liquefaction Reactivity and ${ }^{13}$ C-NMR of Coals Rich in Barkinite and Semifusinite // J. Fuel Chem. Technol. - 2010. - V. 38. - N 2. - P. 129-133.

20. Yoshida I, Tokuhashi K, Maekawa Y. Liquefaction Reaction of Coal: 1. Depolymerization of Coal by Cleavages of Ether and Methylene Bridges // Fuel. - 1985. - V. 64. - N 7. - P. 890-896.

21. Snape C.E. Liquid Fuels and Chemical Feedstocks // Coal in the 21st Century: Energy Needs, Chemicals and Environmental Controls (R.E. Hester and R.M. Harrison, Eds.). - London (UK): The Royal Society of Chemistry, 2018. - P. 173-197. 
22. Ibrahim M.M., Seehra M.S., Kegh R.A. Comparison of the Liquefaction Yields of Coals with Their Composition, Free Radical Density and Thermal Parameters // Fuel Process. Technol. - 1990. - V. 25. - N 3. P. 215-226.

23. Gray D., Barrass G., Jezko J., Kershaw J.R. Relations between Hydroliquefaction Behavior and the Organic Properties of a Variety of South African Coals // Fuel. - 1980. - V. 59. - N 3. - P. 146-150.

24. Marco I., Chomon M.J., Legarreta J.A., Arias P.L. Relationship between Liquefaction Yield and Characteristics of Different Rank Coals // Fuel Process. Technol. - 1990. - V. 24. - P. 127-133.

25. Cudmore J.F. Non-Catalytic Hydrogenation of Australian Coals // Fuel Process. Technol. - 1977/1978. - V. 1. - N 3. - P. 227-241.

26. Cui H., Yang J., Liu Z., Bi J. Effects of Remained Catalysts and Enriched Coal Minerals on Devolatilization of Residual Chars from Coal Liquefaction // Fuel. - 2002. - V. 81. - NN 11-12. - P. 15251531.

27. Burgess C.E., Schobert H.H. Effect of Coal Characteristics and Molybdenum Sulfide Catalyst on Conversions and Yields of Heavy Products from Liquefaction in Phenanthrene // Energy \& Fuels. - 1996. - V. 10. - N 3. - P. 718-725.

28. Speight J.G. The Chemistry and Technology of Coal. $3^{\text {rd }}$ Edition. - Boca Raton/London/New York: CRC Press, Taylor \& Francis Group, 2013. - 845 p.

29. Gray D., Barrass G., Jezko J., Kershaw J.R. South African Coals and Their Behavior During Liquefaction // Coal Liquefaction Fundamentals (Ed. by D.D. Whitehurst). [American Chemical Society Symposium Series. V. 139]. Washington (DC): ACS, 1980. - P. 35-82.

30. Heng S., Shibaoka M. Hydrogenation of the Inertinite Macerals of Bayswater Coal // Fuel. - 1983. - V. 62. - N 5. - P. 610-612.

31. Wang S., Tang Y., Schobert H.H., Guo Y., Su Y. Petrology and Structural Studies in Liquefaction Reactions of Late Permian Coals from Southern China // Fuel. - 2013. - V. 107. - P. 518-524.

32. Barraza J., Portilla A., Piñeres J. Direct Liquefaction of Vitrinite Concentrates Obtained by Column Flotation // Fuel Process. Technol. - 2011. - V. 92. - N 4. - P. 776-779.

33. G. Djega-Mariadassou G., Brodzki D., Abou Akar A., Cagniant D., Miga K. Catalytic Hydroliquefaction of Coal Macerals: Comparison with Raw Coal // Int. J. Energy Res. - 1994. - V. 18. - N 2. P. 205-214.

34. Finkelman R.B., Dai S., French D. The Importance of Minerals in Coal as the Hosts of Chemical Elements: A Review // Int. J. Coal Geol. - 2019. - V. 212. - Article 103251.

35. Ward C.R. Analysis, Origin and Significance of Mineral Matter in Coal: An Updated Review // Int. J. Coal Geol. - 2016. - V. 165. - P. 1-27.

36. Gorbaty M.L. Prominent Frontiers of Coal Science: Past, Present and Future // Fuel. - 1994. - V. 73. N 12. - P. 1819-1828.

37. Mukherjee D.K., Chowdhury P.B. Catalytic Effect of Mineral Matter Constituents in a North Assam Coal on Hydrogenation // Fuel. - 1976. - V. 55. - N 1. - P. 4-8.

38. Guin J.A., Tarrer A.R., Prather J.W., Johnson D.R., Lee J.M. Effects of Coal Minerals on the Hydrogenation, Desulfurization, and Solvent Extraction of Coal // Ind. Eng. Chem. Process Des. Dev. - 1978. V. 17. - N 2. - P. 118-126.

39. Li W., Bai Z.-Q., Bai J., Li X. Transformation and Roles of Inherent Mineral Matter in Direct Coal Liquefaction: A Mini-Review // Fuel. - 2017. - V. 197. - P. 209-216.

40. Garg D., Givens E.N. Pyrite Catalysis in Coal-Liquefaction // Ind. Eng. Chem. Proc. Des. Dev. - 1982. - V, 21. - N 1. - P. 113-117.

41. Gözmen B., Artok L., Erbatur G., Erbatut O.. Direct Liquefaction of High-Sulfur Coals: Effects of the Catalyst, the Solvent, and the Mineral Matter // Energy \& Fuels. - 2002. - V. 16. - N 5. - P. 1040-1047.

42. Fu Y. Guo Y., Zhang K. Effect of Three Different Catalysts $\left(\mathrm{KCl}, \mathrm{CaO}\right.$, and $\left.\mathrm{Fe}_{2} \mathrm{O}_{3}\right)$ on the Reactivity and Mechanism of Low-Rank Coal Pyrolysis // Energy \& Fuels. - 2016. - V. 30. - N 3. - P. 2428-2433.

43. Oner M., Oner G., Bolat E., Yalin G., Kavlak C., Dincer S. The Effect of Ash and Ash Constituents on the Liquefaction Yield of Turkish Lignites and Asphaltites // Fuel. - 1994. - V. 73. - N 10. - P. 1658-1666. 
44. Li X., Bai Z.-Q., Bai J., Zhao B.-B., Li P., Han Y.-N., Kong L.-X., Li W. Effect of Ca ${ }^{2+}$ Species with Different Modes of Occurrence on Direct Liquefaction of a Calcium-Rich Lignite // Fuel Process. Technol. 2015. - V. 133. - P. 161-166.

45. Sugano M., Hirano K., Mashimo K. Comparison of Catalytic Effects of Metals Derived from CationExchanged Coal and Oil Soluble Complex upon Liquefaction of Low Rank Coal // Ind. \& Eng. Chem. Res. 2010. - V. 49. - N 3. - P. 1138-1142.

46. Kou J.-W., Bai Z.-Q., Bai J., Guo Z.-X., Li W. Effects of Mineral Matter and Temperatures on Conversion of Carboxylic Acids and Their Derivatives during Pyrolysis of Brown Coals // Fuel Process. Technol. - 2016. - V. 152. - P. 46-55.

\section{REFERENCES}

1. Kaneko T., Derbyshire F., Makino E., Gray D., M. Tamura M. Coal Liquefaction // Ullmann's Encyclopedia of Industrial Chemistry. V. 9. - Weinheim (Germany): Wiley-VCH, 2012. - P. 311-389.

2. Burgess Clifford C., Song C.. Direct Liquefaction (DCL) Processes and Technology for Coal and Biomass Conversion. Science and Technology // Advances in Clean Hydrocarbon Fuel Processing. - New Delhi (India): Woodhead Publ. Ltd., 2011. - P. 105-154.

3. Van Heek K H, Strobel B O, Wanzl W. Coal Utilization Processes and Their Application to Waste Recycling and Biomass Conversion // Fuel. - 1994. - V. 73. - N 7. - P. 1135-1143.

4. Derbyshire F.J., Whitehurst D.D. Study of Coal Conversion in Polycondensed Aromatic compounds // Fuel. - 1981. - V. 60. - N 8. - P. 655-662.

5. Haenel M.W. Catalysis in Direct Coal Liquefaction // Handbook of Heterogeneous Catalysis. V. 6. Energy-Related Catalysis (G. Ertl, H. Knözinger, F. Schüth and J. Weitkamp, Eds.). $2^{\text {nd }}$ Edition. Weinheim (Germany): Wiley-VCH, 2008. - P. 3023-3036.

6. Rosal R., Diez F.V., Sastre H. Hydrogen-Transferring Liquefaction of Two Different Rank Coals Employing Hydrogenated Anthracene Oil as a Donor Solvent // Ind. \& Eng. Chem. Res. - 1992. - V. 31. - P. 2407-2412.

7. Snape C.E., Derbyshire F.J., Stephens H.P., Kottenstette R.J., Smith N.W. Influence of Organic Coal Structure on Liquefaction Behaviour: An Update with Emphasis on Low Severity Conditions // Fuel Process. Technol. - 1990. - V. 24. - P. 119-125.

8. Vasireddy S., Morreale B., Cugini A., Song C., Spivey J.J. Clean Liquid Fuels from Direct Coal Liquefaction: Chemistry, Catalysis, Technological Status and Challenges // Energy \& Environ. Sci. - 2011. - V. 4. - N 2. - P. 311-345.

9. Neavel R.C. Exxon Donor Solvent Liquefaction Process // Philos. Trans. R. Soc. London. Ser. A, 1981. - V. 300. - N 1353. - P. 141-156.

10.Petrov I.Y., Ushakov K.Y., Bogomolov A.R., Tryasunov B.G. Catalytic Liquefaction of Coals - A Promising Way to Produce Motor Fuels and Valuable Chemical Compounds. Part 2. Coal Structures and Chemistry of Their Direct Liquefaction Processes // Vestnik of Kuzbass State Technical University. - 2020. - N 5 (141). - P. 33-46. (rus).

11.Neavel R.C. Coal Plasticity Mechanism: Inferences from Liquefaction Studies // Coal Science (M. L. Gorbaty, J.W. Larsen, and J. Wender, Eds.). V. 1. - New York: Academic Press, 1982. - P. 1-19.

12.Lee J.M., Cantrell C.E. Effect of Coal Rank and Quality on Two-Stage Liquefaction // Fuel Process. Technol. - 1991. - V. 29. - N 3. - P. 171-197.

13.Kabe T., Horimatsu T., Ishihara A., Kameyama H., Yamamoto K. Tritium as a Tracer in Coal Liquefaction. 4. Hydrogen-Exchange Reactions between Hydrogen in Coals and Tritiated Hydrogen Molecule // Energy \& Fuels. - 1991. - V. 5. - N 3. - P. 459-463.

14.Abdel-Baset M.B., Yarzab R.F., Given P.H. Dependence of Coal Liquefaction Behaviour on Coal Characteristics. 3. Statistical Correlations of Conversion in Coal-Tetralin Interactions // Fuel. - 1978. - V. 57. N 2. - P. 89-94.

15.Snape C.E. Characterisation of Organic Coal Structure for Liquefaction // Fuel Process. Technol. 1987. - V. 15. - P. 257-279.

16.Khimiya i pererabotka uglya [Chemistry and Coal Processing] / V.G. Lipovich [i dr.] (Ed. by V.G. Lipovich). - M.: Khimiya, 1988. - 336 p. (rus)

17.Marshall C., Large D.J., Meredith W., Snape C.E., Uguna C., Spiro B.F., Orheim A., Jochmann M., Mokogwu I., Wang Y., Friis B. Geochemistry and Petrology of Palaeocene Coals from Spitzbergen - Part 1: Oil 
Potential and Depositional Environment // J. Coal Geol. - 2015. - V. 143. - P. 22-33.

18.Wang S., Tang Y., Schobert H.H., Jiang D., Sun Y., Guo Y., Su Y., Yang S. Application and Thermal Properties of Hydrogen-Rich Bark Coal // Fuel. - 2015. - V. 162. - P. 121-127.

19.Wang S., Tang Y., Schobert H.H., Guo Q., Wang F. Liquefaction Reactivity and ${ }^{13}$ C-NMR of Coals

Rich in Barkinite and Semifusinite // J. Fuel Chem. Technol. - 2010. - V. 38. - N 2. - P. 129-133.

20.Yoshida I, Tokuhashi K, Maekawa Y. Liquefaction Reaction of Coal: 1. Depolymerization of Coal by Cleavages of Ether and Methylene Bridges // Fuel. - 1985. - V. 64. - N 7. - P. 890-896.

21.Snape C.E. Liquid Fuels and Chemical Feedstocks // Coal in the 21st Century: Energy Needs, Chemicals and Environmental Controls (R.E. Hester and R.M. Harrison, Eds.). - London (UK): The Royal Society of Chemistry, 2018. - P. 173-197.

22.Ibrahim M.M., Seehra M.S., Kegh R.A. Comparison of the Liquefaction Yields of Coals with Their Composition, Free Radical Density and Thermal Parameters // Fuel Process. Technol. - 1990. - V. 25. - N 3. P. 215-226.

23.Gray D., Barrass G., Jezko J., Kershaw J.R. Relations between Hydroliquefaction Behavior and the Organic Properties of a Variety of South African Coals // Fuel. - 1980. - V. 59. - N 3. - P. 146-150.

24.Marco I., Chomon M.J., Legarreta J.A., Arias P.L. Relationship between Liquefaction Yield and Characteristics of Different Rank Coals // Fuel Process. Technol. - 1990. - V. 24. - P. 127-133.

25.Cudmore J.F. Non-Catalytic Hydrogenation of Australian Coals // Fuel Process. Technol. - 1977/1978. - V. 1. - N 3. - P. 227-241.

26.Cui H., Yang J., Liu Z., Bi J. Effects of Remained Catalysts and Enriched Coal Minerals on Devolatilization of Residual Chars from Coal Liquefaction // Fuel. - 2002. - V. 81. - NN 11-12. - P. 1525 1531.

27.Burgess C.E., Schobert H.H. Effect of Coal Characteristics and Molybdenum Sulfide Catalyst on Conversions and Yields of Heavy Products from Liquefaction in Phenanthrene // Energy \& Fuels. - 1996. - V. 10. - N 3. - P. 718-725.

28.Speight J.G. The Chemistry and Technology of Coal. $3^{\text {rd }}$ Edition. - Boca Raton/London/New York: CRC Press, Taylor \& Francis Group, 2013. - 845 p.

29.Gray D., Barrass G., Jezko J., Kershaw J.R. South African Coals and Their Behavior During Liquefaction // Coal Liquefaction Fundamentals (Ed. by D.D. Whitehurst). [American Chemical Society Symposium Series. V. 139]. Washington (DC): ACS, 1980. - P. 35-82.

30.Heng S., Shibaoka M. Hydrogenation of the Inertinite Macerals of Bayswater Coal // Fuel. - 1983. - V. 62. - N 5. - P. 610-612.

31.Wang S., Tang Y., Schobert H.H., Guo Y., Su Y. Petrology and Structural Studies in Liquefaction Reactions of Late Permian Coals from Southern China // Fuel. - 2013. - V. 107. - P. 518-524.

32.Barraza J., Portilla A., Piñeres J. Direct Liquefaction of Vitrinite Concentrates Obtained by Column Flotation // Fuel Process. Technol. - 2011. - V. 92. - N 4. - P. 776-779.

33.G. Djega-Mariadassou G., Brodzki D., Abou Akar A., Cagniant D., Miga K. Catalytic Hydroliquefaction of Coal Macerals: Comparison with Raw Coal // Int. J. Energy Res. - 1994. - V. 18. - N 2. P. 205-214.

34.Finkelman R.B., Dai S., French D. The Importance of Minerals in Coal as the Hosts of Chemical Elements: A Review // Int. J. Coal Geol. - 2019. - V. 212. - Article 103251.

35.Ward C.R. Analysis, Origin and Significance of Mineral Matter in Coal: An Updated Review // Int. J. Coal Geol. - 2016. - V. 165. - P. 1-27.

36.Gorbaty M.L. Prominent Frontiers of Coal Science: Past, Present and Future // Fuel. - 1994. - V. 73. N 12. - P. 1819-1828.

37.Mukherjee D.K., Chowdhury P.B. Catalytic Effect of Mineral Matter Constituents in a North Assam Coal on Hydrogenation // Fuel. - 1976. - V. 55. - N 1. - P. 4-8.

38.Guin J.A., Tarrer A.R., Prather J.W., Johnson D.R., Lee J.M. Effects of Coal Minerals on the Hydrogenation, Desulfurization, and Solvent Extraction of Coal // Ind. Eng. Chem. Process Des. Dev. - 1978. V. 17. - N 2. - P. 118-126.

39.Li W., Bai Z.-Q., Bai J., Li X. Transformation and Roles of Inherent Mineral Matter in Direct Coal Liquefaction: A Mini-Review // Fuel. - 2017. - V. 197. - P. 209-216.

40.Garg D., Givens E.N. Pyrite Catalysis in Coal-Liquefaction // Ind. Eng. Chem. Proc. Des. Dev. - 1982. $-\mathrm{V}, 21 .-\mathrm{N} 1 .-$ P. 113-117.

41.Gözmen B., Artok L., Erbatur G., Erbatut O.. Direct Liquefaction of High-Sulfur Coals: Effects of the 
Catalyst, the Solvent, and the Mineral Matter // Energy \& Fuels. - 2002. - V. 16. - N 5. - P. 1040-1047. 42.Fu Y. Guo Y., Zhang K. Effect of Three Different Catalysts $\left(\mathrm{KCl}, \mathrm{CaO}\right.$, and $\left.\mathrm{Fe}_{2} \mathrm{O}_{3}\right)$ on the Reactivity and Mechanism of Low-Rank Coal Pyrolysis // Energy \& Fuels. - 2016. - V. 30. - N 3. - P. 2428-2433.

43.Oner M., Oner G., Bolat E., Yalin G., Kavlak C., Dincer S. The Effect of Ash and Ash Constituents on the Liquefaction Yield of Turkish Lignites and Asphaltites // Fuel. - 1994. - V. 73. - N 10. - P. 1658-1666.

44.Li X., Bai Z.-Q., Bai J., Zhao B.-B., Li P., Han Y.-N., Kong L.-X., Li W. Effect of $\mathrm{Ca}^{2+}$ Species with Different Modes of Occurrence on Direct Liquefaction of a Calcium-Rich Lignite // Fuel Process. Technol. 2015. - V. 133. - P. 161-166.

45.Sugano M., Hirano K., Mashimo K. Comparison of Catalytic Effects of Metals Derived from CationExchanged Coal and Oil Soluble Complex upon Liquefaction of Low Rank Coal // Ind. \& Eng. Chem. Res. 2010. - V. 49. - N 3. - P. 1138-1142.

46.Kou J.-W., Bai Z.-Q., Bai J., Guo Z.-X., Li W. Effects of Mineral Matter and Temperatures on Conversion of Carboxylic Acids and Their Derivatives during Pyrolysis of Brown Coals // Fuel Process.

Technol. - 2016. - V. 152. - P. 46-55.

\section{Библиографическое описание статьи}

Петров И.Я., Осипов А.В., Ушаков К.Ю., Богомолов А.Р., Трясунов Б.Г. Каталитическое ожижение углей - перспективный способ производства моторных топлив и ценных химических соединений/ Часть 3. факторы, влияющие на процессы ожижения углей: степень углефикации и состав угля // Вестник Кузбасского государственного технического университета. - 2021. - № 3 (145). - С. 58-73.

\section{Reference to article}

Petrov I.Y., Osipov A.V., Ushakov K.Y., Bogomolov A.R., Tryasunov B.G. Catalytic liquefaction of coals - a promising way to produce motor fuels and valuable chemical compounds/ Part 3. factors influencing the processes of coal liquefaction: coal rank and coal composition. Bulletin of the Kuzbass State Technical University, 2021, no.3 (145), pp. 5873. 